\title{
Estimated Prevalence of Advanced Hepatic Fibrosis by Elastography in Patients with Type 2 Diabetes
}

ISSN: 2578-0263

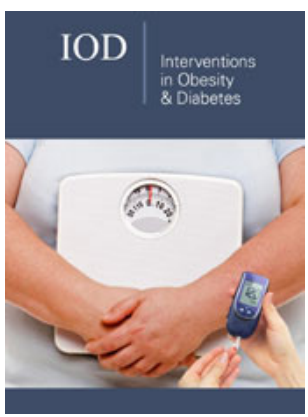

*Corresponding author: Yoshio Sumida, Division of Hepatology and Pancreatology, Department of Internal Medicine, Aichi Medical University, Nagakute, Japan

Submission: 进 February 11, 2020

Published: 趼February 20, 2020

Volume 3 - Issue 4

How to cite this article: Yoshio Sumida, Masashi Yoneda, Katsutoshi Tokushige, Miwa Kawanaka, Hideki Fujii, et al. Estimated Prevalence of Advanced Hepatic Fibrosis by Elastography in Patients with Type 2 Diabetes. Interventions Obes Diabetes 3(4). IOD.000570.2020. DOI: 10.31031/IOD.2020.03.000570

Copyright@ Yoshio Sumida. This article is distributed under the terms of the Creative Commons Attribution 4.0 International License, which permits unrestricted use and redistribution provided that the original author and source are credited.
Yoshio Sumida ${ }^{1 *}$, Masashi Yoneda $^{1}$, Katsutoshi Tokushige ${ }^{2}$, Miwa Kawanaka $^{3}$, Hideki Fujiii ${ }^{4}$, Masato Yoneda ${ }^{5}$, Kento Imajo ${ }^{5}$, Hirokazu Takahashi ${ }^{6}$, Yuichiro Eguchi $^{6}$, Masafumi Ono ${ }^{7}$, Yuichi Nozaki ${ }^{8}$, Hideyuki Hyogo ${ }^{9}$, Masahiro Koseki ${ }^{10}$, Yuichi Yoshida $^{11}$, Takumi Kawaguchi ${ }^{12}$, Yoshihiro Kamada ${ }^{13}$, Takeshi Okanoue ${ }^{14}$ , Atsushi Nakajima ${ }^{5}$ and Japan Study Group of NAFLD (JSG-NAFLD)

${ }^{1}$ Division of Hepatology and Pancreatology, Department of Internal Medicine, Aichi Medical University, Japan

${ }^{2}$ Department of Internal Medicine, Institute of Gastroenterology, Tokyo Women's Medical University, Tokyo, Japan

${ }^{3}$ Department of General Internal Medicine, Kawasaki Medical School, Japan

${ }^{4}$ Department of Hepatology, Graduate School of Medicine, Osaka City University, Osaka, Japan

${ }^{5}$ Division of Gastroenterology, Yokohama City University Graduate School of Medicine, Yokohama, Japan

${ }^{6}$ Department of Internal Medicine, Saga Medical School, Saga University, Saga, Japan

${ }^{7}$ Division of Gastroenterology and Hepatology, Department of Internal Medicine, Tokyo Women's Medical University Medical Center East, Tokyo, Japan

${ }^{8}$ Department of Gastroenterology, National Center for Global Health and Medicine, Tokyo, Japan.

${ }^{9}$ Department of Gastroenterology, JA Hiroshima Kouseiren General Hospital, Japan

${ }^{10}$ Department of Cardiovascular Medicine, Osaka University Graduate School of Medicine

${ }^{11}$ Department of Gastroenterology, Suita City Hospital, Osaka, Japan

${ }^{12}$ Division of Gastroenterology, Department of Medicine, Kurume University School of Medicine, Kurume, Japan

${ }^{13}$ Department of Molecular Biochemistry \& Clinical Investigation, Osaka University Graduate School of Medicine, Suita, Osaka, Japan

${ }^{14}$ Hepatology Center, Saiseikai Suita Hospital, Japan

\section{Abstract}

Nonalcoholic fatty liver disease (NAFLD) is the most common chronic liver disease. The grade of hepatic fibrosis is known to be closely associated with over-all or liver-related mortality in NAFLD. In order to detect early stage of hepatocellular carcinoma (HCC), it is essential to identify advanced hepatic fibrosis in NAFLD. To avoid invasive liver biopsies, several modalities have developed for evaluating hepatic fibrosis, including elastography (FibroScan and magnetic resonance elastography) and noninvasive tests (NITs) such as fibrosis-4 index and NAFLD fibrosis score. Patients with type 2 diabetes is twice at higher risk for incident HCC compared to the non-diabetic population. Although type 2 diabetes is also associated with fibrosis progression of NAFLD, the precise prevalence of advanced hepatic fibrosis in type 2 diabetes remains unknown. To detect or prevent the development of HCC in type 2 diabetes, mining patients with advanced fibrosis (stage $3 / 4$ ) is important. It is estimated that approximately $17 \%$ of patients with type 2 diabetes receiving liver biopsies had advanced fibrosis. Population-based data are essential because of excluding selection bias. In this review, we review estimated prevalence of advanced hepatic fibrosis in patients with type 2 diabetes by using non-invasive elastography.

Keywords: Diabetes, Hepatic fibrosis, Elastography, Fibroscan, Magnetic resonance elastography

Abbreviations: NAFLD: Nonalcoholic Fatty Liver Disease; HCC: Hepatocellular Carcinoma; NITs: Noninvasive Tests; ARFI: Acoustic Radiation Force Impulse; MRE: Magnetic Resonance Elastography

\section{Introduction}

Hepatocellular carcinoma (HCC) is the fifth most common cancer and the second leading cause of cancer-related death worldwide. The main etiology of HCC has been hepatitis virus infection for several decades. The development of anti-hepatitis viral agents, including direct acting antivirals for hepatitis $\mathrm{C}$ virus (HCV) or nucleoside analogues for hepatitis $\mathrm{B}$ virus 
(HBV), can lead to decrease in incidence of HCC worldwide [1]. In Japan, the prevalence of so-called "non-HBV, non-HCV HCC (NBNCHCC)" has been increasing (32.5\% of HCC in 2015) [2]. An estimated 400 million individuals have diabetes worldwide, among whom 85-95\% have type 2 diabetes (T2D). There is emerging evidence of a link between T2D and an increased risk of developing cancer and death from cancer. In a meta-analysis of 13 case-control and 13 cohort studies, diabetes was associated with increased HCC risk (odds ratio [OR]:2.5 and hazard ratio [HR]:2.5) [3]. A more recent meta-analysis of 23 cohort studies reported a pooled relative risk (RR) of 2.0 [4]. In recent two large cohorts of U.S. men and women, with over 26 year of follow-up, T2D is significantly associated with incident HCC. This risk was enhanced in patients with a prolonged duration of T2D, and in those with an increasing number of comorbid metabolic conditions (dyslipidemia, obesity, and hypertension) [5]. $\mathrm{T}_{2} \mathrm{D}$ was associated with a $26 \%$ increased risk of death from any cancer also in Asians. The HR of HCC is 2.05 [6]. In Japan, Nakamura and colleagues demonstrated that HCC was the fifth leading causes of mortality (6.0\%) in 45,708 Japanese diabetic patients at 241 hospitals during 2001-2010 [7]. Since the tenth cause is liver cirrhosis (3.3\%), 9.3\% of diabetic patients totally died from liver related diseases in Japan. It is important to identify those patients with T2D who have a high risk of developing HCC. Risk factors for incident HCC in T2D patients have not been established. Three parameters which are associated with HCC incidence are old age ( $>65 \mathrm{yr}$ ), low triglyceride level $(<150 \mathrm{mg} / \mathrm{dl})$ and high gamma-glutamyl transferase (GGT) level (>40IU/L) [8]. A multicenter study from Japan by Korenaga and colleagues demonstrated that the SNPs of PNPLA3 and juxtaposed with another zinc finger protein 1 (JAZF1) were associated with development of HCC in T2DM patients without hepatitis virus infection [9]. That study included 389 T2D patients, including 59 patients with HCC (T2D-HCC) and 330 patients without HCC (T2D-non-HCC). Compared to T2D-non-HCC patients, T2D-HCC patients had the significantly higher frequency of the PNPLA3 $\mathrm{G}$ allele $\left(\mathrm{OR}=2.53, \mathrm{P}=1.05 \times 10^{-5}\right.$ ). Moreover, among the 115 T2D patients with PNPLA3 genotype GG, HCC patients had the significantly higher frequency of the JAZF1 rs864745 G allele $(\mathrm{OR}=3.44, \mathrm{P}=0.0002)$. We conclude that SNPs of PNPLA3 and JAZF1 may be associated with an increased risk of developing HCC among T2D patients without viral hepatitis.

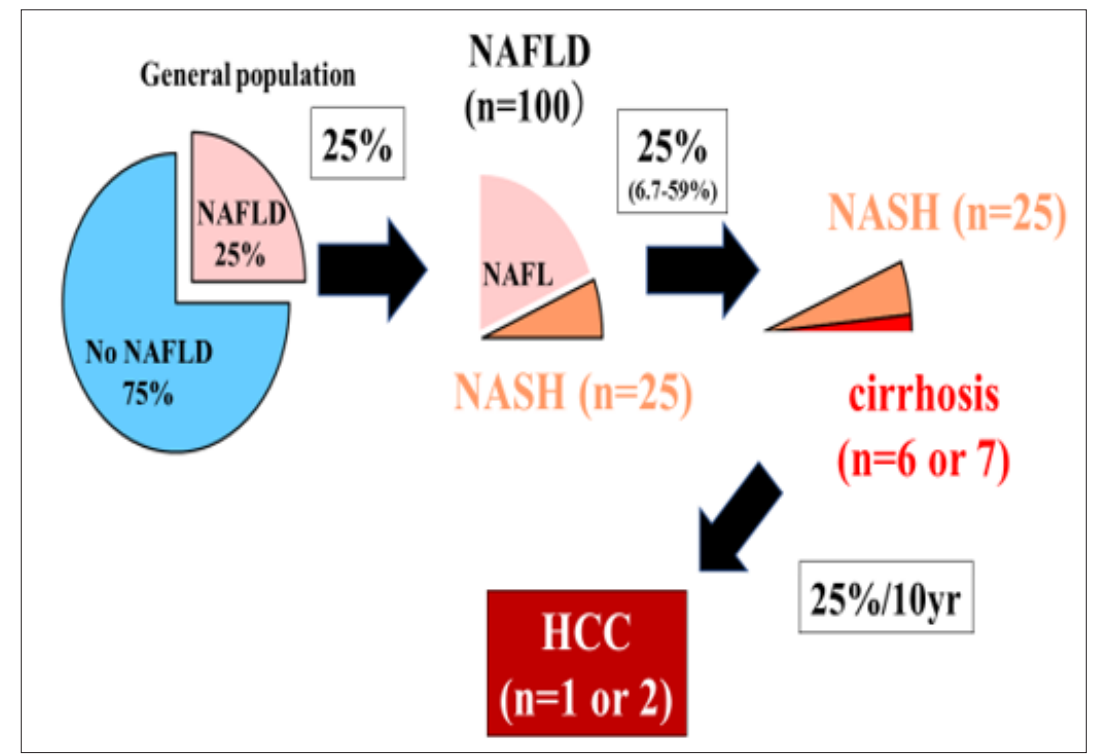

Figure 1: A few patients among 100 NAFLD will develop HCC (25\% rule) [10-14].

Nonalcoholic fatty liver disease (NAFLD) is becoming a major cause of HCC, with a steadily rising trend compared to virus-induced chronic hepatitis. NAFLD is closely associated with T2D. One fourth of the adult population (25\%) is globally suffering from NAFLD [10]. In U.S., across the 6-year period (2004 to 2009), the number of NAFLD-HCC showed a $9 \%$ annual increase. However, the leading cause of NAFLD is cardiovascular disease (42\%) followed by extrahepatic cancer (20\%), and liver-related mortality (9\%) [11] .We believe that a few patients among 100 NAFLD patients will develop HCC [12]; 25\% (6.7-29\%) of NAFLD can progress to NASH [13], 25\% (6.7-29\%) of NASH can lead to cirrhosis, and 25\% of NASH-cirrhosis develop HCC for about 10 years [14] (We name "25\% rule") (Figure 1). Sirtuin-1 (SIRT1) is vital for the physiological function of healthy tissues. SIRT1 deletion in mice hepatocytes results in hepatic steatosis or hepatitis. SIRT1 overexpression reduced the release of pro-inflammatory cytokines and increased cell viability. Previous studies have reported that hepatic SIRT1 plays a major role in ameliorating steatosis and inhibiting inflammation in NAFLD by modifying the acetylation status of the different target molecules. SIRT1 can ameliorate liver fibrosis by blocking hepatic stellate cell activation in mice. Impact of expression of SIRT1 on hepatocarcinogenesis of NAFLD is conflicting. In the future, it should be clarified whether plasma SIRT1 levels or histological SIRT1 expression may be relevant to NAFLD, advanced hepatic fibrosis, and HCC [15-19]. The several risk factors for incident HCC in ultrasonography (US) diagnosed NAFLD from a Japanese cohort are identified, including serum AST level $\geq 40$ IU/L (HR:8.20; 95\% CI:2.5626.26; $\mathrm{P}<0.001$ ), platelet count $<150 \times 10^{3} / \mu \mathrm{l}$ (HR: 7.19; $95 \% \mathrm{CI}$ : 
2.26-23.26; $\mathrm{P}=0.001$ ), age $\geq 60$ years (HR:4.27; 95\% CI:1.30-14.01; $\mathrm{P}=0.017$ ), and T2D (HR:3.21; 95\% CI:1.09-9.50; P=0.035) [20]. In our Japanese cohort with biopsy proven NAFLD ( $n=238)$, severe fibrosis (F3/4) and PNPLA3 GG genotype were predictors of HCC development, independent of other known risk factors [21]. Advanced hepatic fibrosis is well known to be the most important risk factors for not only incident HCC but also liver related mortality in NAFLD [22]. Therefore, it is important to identify patients with advanced fibrosis in NAFLD to improve overall survival. Liver biopsy is the gold standard for diagnosis of hepatic fibrosis in NAFLD. Fibrosis stage is classified by Brunt or NASH Clinical Research Network system (stage 0-4). In general, advanced fibrosis is defined stage 3/4. Liver biopsy has several drawbacks such as risks, sampling error, observers' variability, cost and patients' unwillingness. Thus, noninvasive tests (NITs) or elastography have been established to avoid liver biopsies [23]. We here review to estimate prevalence of advanced hepatic fibrosis by elastography in patients with T2D.

\section{Evaluation Method of Hepatic Fibrosis using Elastogra-} phy

\section{Vibration-controlled transient elastography (VCTE)}

To assess liver fibrosis, several noninvasive US-based elastography techniques have been developed. These methods include VCTE (FibroScan; Echosens, Paris, France), acoustic radiation force impulse imaging and shear wave elastography. US-based VCTE performed with the FibroScan (Echosens) is the most thoroughly validated and commonly used elastography method worldwide [24-33]. VCTE is equipped with a one-dimensional probe and an ultrasonic transducer mounted on the axis of a vibrator. A vibration of mild amplitude and low frequency is transmitted from the vibrator onto the tissue by the transducer itself, which induces propagation of an elastic shear wave through the tissue. The propagation velocity is directly related to the stiffness of the medium, defined by the Young modulus expressed in kilopascals $(\mathrm{E} \fallingdotseq 3 \rho \mathrm{Vs} 2)$. VCTE was developed approximately 10 years ago as the first US-based elastography method. It has since been validated for liver fibrosis assessment and was recently included in the European Association for the Study of the Liver Guidelines for fibrosis assessment in patients with chronic B and C hepatitis infection. Furthermore, VCTE received approval from the United States Food and Drug Administration on 5 April 2013, and it is expected that its use will subsequently increase not only in Europe but also the United States. A systematic review and meta-analysis of VCTE in patients with NAFLD by Kwok et al. indicated that VCTE is good for the diagnosis of stage 3 fibrosis (85\% sensitivity and $82 \%$ specificity) and excellent for stage 4 (92\% sensitivity and $92 \%$ sensitivity). However, it has a slightly lower accuracy for diagnosing stage 2 fibrosis (79\% sensitivity and 75\% specificity) [34]. The benefits of VCTE include its rapidity and painlessness, quick availability of the result, high intraand inter-operator reproducibility (intra-class correlation coefficient [ICC] of 0.98) [35], and good diagnostic accuracy that has been validated in many studies. Clinical use of VCTE has generally been limited because of its high failure rate or unreliable results. These limitations are commonly a result of obesity, operator inexperience, narrow intercostal spaces, a thick chest wall, and ascites [36,37]. In a previously published study, the rate of failed and unreliable measurements by VCTE using the standard M probe was $5.8 \%$ to $29.2 \%$ $[37,38]$. To improve this problem, the VCTE device has three different probes for measurement in various circumstances: The $S$ probe $(5.0 \mathrm{MHz})$ for children, the $\mathrm{M}$ probe $(3.5 \mathrm{MHz})$ for adults, and the $\mathrm{XL}$ probe $(2.5 \mathrm{MHz})$ for overweight patients.

\section{Magnetic resonance elastography}

Magnetic resonance elastography (MRE) is a noninvasive magnetic resonance imaging (MRI)-based method measuring liver stiffness by using a modified phase-contrast method. MRE can assess the entire liver with a high success rate. MRE is not operator dependent or affected by obesity or ascites and is currently the most accurate imaging tool for the detection of liver fibrosis, more effective than TE alone or TE with serum biomarkers combined [39-45]. Two imaging modalities were compared in Table 1.

Table 1: Elastography (MR elastography vs. VCTE)

\begin{tabular}{|c|c|c|}
\hline \multirow[b]{2}{*}{ Modality } & MR elastography & VCTE \\
\hline & & \\
\hline Strength & $\begin{array}{c}\cdot \text { Accuracy for identify hepatic fibrosis } \\
\cdot \text { Not affected by obesity or ascites } \\
\text { - Can also evaluate steatosis (using PDFF), inflammation (using multi- } \\
\text { parametric MRI), iron deposit, and the existence of HCC } \\
\cdot \text { Good reproducibility } \\
\cdot \text { Relatively high cost }\end{array}$ & $\begin{array}{c}\cdot \text { Convenience } \\
\cdot \text { Short processing time } \\
\cdot \text { Portability } \\
\cdot \text { Relatively low cost } \\
\cdot \text { Can also evaluate steatosis (using CAP) } \\
\cdot \text { Covered by health insurance (in Japan) }\end{array}$ \\
\hline
\end{tabular}


- Contraindicated in patients with pacemaker or claustrophobia - Time consuming - Not covered by health insurance (in Japan)

\section{- Operator dependency}

- Influenced by obesity, congestion, and inflammation - Difficulty in patients with obesity and ascites - Observer's variability

Abbreviations: MR: Magnetic Resonance; VCTE: Vibration Controlled Transient Elastography; MRI: Magnetic Resonance Imaging; PDFF: Proton Density Fat Fraction; HCC: Hepatocellular Carcinoma; CAP: Controlled Attenuation Parameter

The Relationship between Hepatic Fibrosis and Type 2 Diabetes

\section{Cross sectional studies}

Angulo and colleagues from U.S. showed that $\mathrm{T}_{2} \mathrm{D}$ was independently associated with severe fibrosis in NAFLD [46]. According to a large cohort $(n=1,365)$ from a multi-center study by Japan Study Group of NAFLD (JSG-NAFLD), the existence of T2D was closely associated with liver fibrosis severity in Japanese patients with NASH [47]. On the basis of a cohort with biopsy-proven NAFLD from JSG-NAFLD ( $n=361$ ), HOMA-IR ( $>2.90)$ were found to be independent predictors of advanced fibrosis in the estimation and validation group [48]. According to data from 262 Germen patients with non-cirrhotic NAFLD on liver biopsy, multivariate logistic regression demonstrated that diabetes (odds ratio $[\mathrm{OR}]=4.68,95 \%$ confidence interval [CI] 2.17-10.10) and hypertension (OR=2.91, $95 \%$ CI 1.12-7.18) were independently associated with advanced hepatic fibrosis [49]. In this way T2D or insulin resistance must be associated with advanced hepatic fibrosis in NAFLD.

\section{Longitudinal studies}

Adams et al. reported that $\mathrm{T}_{2} \mathrm{D}$ and low initial fibrosis stage are associated with a higher rate of fibrosis progression in 103 NAFLD patients who underwent serial liver biopsies with a mean interval of $3.2 \pm 3.0$ years between biopsies [50]. In Japanese NAFLD cohort, the presence of $\mathrm{T}_{2} \mathrm{D}$ was an independent risk factor for progression to advanced liver fibrosis (HR, 1.879) evaluated by fibrosis-4 (FIB-4) index in addition to advanced age and low albumin concentration [51]. Furthermore, longer duration of T2DM has also been reported to be an independent risk factor for progressive fibrosis in patients with NAFLD [52]. Hamaguchi and colleagues showed that the change in glycated hemoglobin $(\triangle \mathrm{HbA} 1 \mathrm{c})$ was strongly associated with serial change of hepatic fibrosis based on data of NAFLD patients with T2D receiving repeat liver biopsies [53]. They recommend that strict diabetic control is required for inhibiting fibrosis progression in NAFLD patients with T2D. In a prospective cohort study of 40,700 adults with NAFLD, obesity and weight gain are independently associated with increased risk of fibrosis progression, based on APRI [54]. In 80 NASH patients who had undergone serial liver biopsies in this retrospective cohort study, poor response of alanine aminotransferase (ALT) levels, increase in HbA1c levels, and presence of the tumor necrosis factor risk allele in the rs1799964 SNP were identified as independent risk factors contributing to histological progression in NASH patients [55]. MRE can also reflect hepatic fibrosis after pharmacotherapies.

\section{Estimated Prevalence of Advanced Hepatic Fibrosis by Elastography in Patients with Type 2 Diabetes}

Table 2: Estimated prevalence of significant/advanced hepatic fibrosis by elastography in patients with type 2 diabetes.

\begin{tabular}{|c|c|c|c|c|c|c|}
\hline Imaging Modalities & Author & Paper & $\mathbf{N}$ & COI & Prevalence & Risk factors \\
\hline \multirow{10}{*}{ VCTE } & $\begin{array}{l}\text { de Ledinghen [58] } \\
\text { (France) }\end{array}$ & Dig Liver Dis 2012 & 277 (TIDM: 52\%) & $\geq 8.7 \mathrm{kpa}$ & $15.5 \%$ & $\begin{array}{l}\geq 50 \mathrm{yr} \text {, T2DM. retinopa- } \\
\text { thy (-). No history of leg } \\
\text { ulcer history of leg ulcer }\end{array}$ \\
\hline & $\begin{array}{l}\text { Casey [59] } \\
\text { (Australia) }\end{array}$ & $\begin{array}{l}\text { Scand J Gastroenterol } \\
2012\end{array}$ & 74 & $\geq 7.6 \mathrm{kpa}$ & $35 \%$ & \\
\hline & $\begin{array}{c}\text { Sobbonslidsuk } \\
\text { [60] } \\
\text { (Thailand ) }\end{array}$ & $\begin{array}{l}\text { Asian Pac J Cancer } \\
\text { Prev. } 2015\end{array}$ & 141 & $\geq 7.0 \mathrm{kpa}$ & $16.1 \%$ & \\
\hline & $\begin{array}{l}\text { Kwok [61] } \\
\text { (How Kong) }\end{array}$ & Gut 2016 & 1770 & $\geq 9.6 \mathrm{kpa}$ & $17.1 \%$ & $\begin{array}{c}\text { High body weight (high } \\
\text { BMZ) , WC, BP, TG, FPG, } \\
\text { HbAlc, ALT, Urinary Alb/ } \\
\text { Cr ratio }\end{array}$ \\
\hline & $\begin{array}{l}\text { Roulot [62] } \\
\text { (France) }\end{array}$ & Liver lnt 2017 & 669 & $\begin{array}{l}\geq 8.0 \mathrm{kpa} \\
\geq 9.6 \mathrm{kpa} \\
\geq 13.0 \mathrm{kpa}\end{array}$ & $\begin{array}{l}12.7 \% \\
7.3 \% \\
2.1 \%\end{array}$ & $\begin{array}{c}\text { Age, overweight, } \gamma \text { GTP } \\
\text { elevation }\end{array}$ \\
\hline & $\begin{array}{c}\text { Lai [63] } \\
\text { (Malaysia) }\end{array}$ & $\begin{array}{l}\text { J Gastroenterol Hepa- } \\
\text { tol } 2019\end{array}$ & 557 & $\begin{array}{l}\geq 9.6 \mathrm{kpa} \text { (M.Probe) } \\
\geq 9.3 \mathrm{kpa} \text { (XL.Probe) }\end{array}$ & $21.0 \%$ & HDL-C, ALT, GTP, PLT \\
\hline & $\begin{array}{l}\text { Demir [64] } \\
\text { (Turkey) }\end{array}$ & $\begin{array}{l}\text { Turk J Gastroenterol } \\
2019\end{array}$ & 124 & $\begin{array}{l}\geq 9.6 \mathrm{kpa} \text { (M.Probe) } \\
\geq 9.3 \mathrm{kpa} \text { (XL.Probe) }\end{array}$ & $25 \%$ & \\
\hline & $\begin{array}{l}\text { Mantovani [65] } \\
\text { (Italy) }\end{array}$ & $\begin{array}{c}\text { Diabetes Metab. } \\
2019 \\
\end{array}$ & 137 & $\begin{array}{l}\geq 7.0 \mathrm{kpa} \\
\geq 8.7 \mathrm{kpa}\end{array}$ & $\begin{array}{l}17.5 \% \\
10.2 \% \\
\end{array}$ & \\
\hline & $\begin{array}{l}\text { Mansour [66] } \\
\text { (Iran) }\end{array}$ & Acta Diabetol. 2019 & 108 & $\geq 8.0 \mathrm{kpa}$ & $24.1 \%$ & AST, WC, C.peptide \\
\hline & $\begin{array}{l}\text { Lee HW [67] } \\
\text { (Hong Kong) }\end{array}$ & Hepatology 2020 & 611 & $>10.0 \mathrm{kpa}$ & $20.3 \%$ & \\
\hline
\end{tabular}




\begin{tabular}{|c|c|c|c|c|c|c|}
\hline \multirow{3}{*}{ MRE } & $\begin{array}{c}\text { Doycheva [68] } \\
\text { (US) }\end{array}$ & $\begin{array}{c}\text { Aliment Pharmacol } \\
\text { Ther. 2016 }\end{array}$ & 100 & $\geq 3.6 \mathrm{kpa}$ & $7.1 \%$ & \\
\cline { 2 - 7 } & $\begin{array}{c}\text { Kang KA [69] } \\
\text { (Korean) }\end{array}$ & $\begin{array}{c}\text { Aliment Pharmacol } \\
\text { Ther. 2020 }\end{array}$ & 281 & $\begin{array}{c}\geq 3.0 \mathrm{kpa} \\
\geq 3.6 \mathrm{kpa}\end{array}$ & $\begin{array}{c}12.5 \% \\
4.3 \%\end{array}$ & \\
\hline
\end{tabular}

Abbreviations: Abbreviations: MRE: Magnetic Resonance Elastography; VCTE: Vibration Controlled Transient Elastography; BMI: Body Mass Index; WC: Waist Circumference; BP: Body Pressure; TG: Triglyceride; FPG: Fasting Plasma Glucose; HbA1c: Glycated Hemoglobin; Alb: Albumin; Cr: Creatine; YGTP: Gamma Glutamyl Transpeptidase; PLT: Platelet Count; FPG: Fasting Plasma Glucose.

Of the patients with NAFLD and T2D who undergo liver biopsies based on data of seven studies, $17 \%$ (95\% CI 7.2-34.8) have advanced fibrosis [56]. Another study showed that the percentages of advanced fibrosis in biopsyproven NAFLD patients with T2DM were $56.5 \%$ [57]. However, selection bias must exist in these studies using histological diagnosis, because liver biopsy is invasive, expensive procedure, and difficult to be consented by patients. Several studies tried to estimate the true prevalence of advanced hepatic fibrosis by non-invasive elastography in patients with T2D. Most of these studies used VCTE except two studies from US and South Korea (Table 2).

\section{VCTE [58-67]}

Significant hepatic fibrosis (liver stiffness measurement [LS$\mathrm{M}] \geq 7.0 \mathrm{kPa}$ ) was more common in diabetic patients (16.1 or $17.5 \%$ ) [60]. The prevalence of severe hepatic fibrosis ( $\mathrm{LSM} \geq 9.6-10.0 \mathrm{kPa}$ ) is estimated to be $7.3-24.9 \%$. Asian populations tend to have higher prevalence of advanced fibrosis compared to the West, although cutoff value of VCTE for detecting advanced fibrosis is variable. Prevalence of advanced fibrosis may be influenced by the distribution of age, sex, body mass index (BMZ), diabetic control status, and anti-diabetic medications. In a recent study from Hong-Kong, $20.3 \%$ with T2DM showed LSM $>10.0 \mathrm{kPa}$. Among 487 patients with baseline $\mathrm{LSM}<10 \mathrm{kPa}, 21$ (4.3\%) had follow-up $\mathrm{LSM} \geq 10 \mathrm{kPa}$ in 3 years. Baseline BMZ, ALT and $\triangle$ ALT were independent factors associated with LSM increase [67]. Body weight and serum ALT should be strict controlled in NAFLD with T2D.

\section{MR elastography $[68,69]$}

The prevalence of advanced fibrosis seems to be lower by evaluated using MR elastography compared to VCTE. Optimal cutoff values should be settled using these two modalities in an international, multi-center study [68]. The prevalence of F2 ( $\geq 3.0 \mathrm{kPa})$ and F3 $(\geq 3.6 \mathrm{kPa})$ in the overall cohort $(\mathrm{n}=2,170)$ receiving health check-up was $5.1 \%$ and $1.3 \%$ respectively. In patients with diabetes, $12.5 \%$ had $\geq \mathrm{F} 2$ and $4.3 \% \geq \mathrm{F} 3[69]$. The reason why the prevalence of advanced fibrosis seems to be lower in MRE than VCTE remains to be resolved. The plausible examination is that LSM by VCTE might be influenced by a variety of factors such as congestion, steatosis, inflammation, and bile cholestasis. False positive rate is higher in VCTE than MRE. Strengths and weakness of each imaging modality were compared between MRE and VCTE (Table 1). Accuracy and reproducibility are superior in MRE to in VCTE. Moreover, multiparametric MRI can estimate hepatocyte ballooning and inflammation. In contrast, VCTE has several advantages such as portability, short processing time, and relatively low cost. MRE cannot be applied to individuals with hepatic iron overload due to the interfering signal intensity. Moreover, the cost of MRE and its dependence on MRI fa- cilities limit its wide application. Among two imaging modalities, VCTE will be positioned as the $1^{\text {st }}$ triaging tool for excluding no/ mild fibrosis, and MRE is used as confirmed diagnosis by hepatology specialists.

\section{Conclusion}

A significant proportion of patients with T2D is estimated to have underlying advanced fibrosis which was evaluated by elastography (Fibroscan and MR elastography). In order to detect early HCC or prevent incident HCC, patients with T2D should be screened for identifying advanced hepatic fibrosis. Accumulating evidences suggest that $\underline{A} \mathrm{LT}, \underline{b}$ ody weight, HbA1므 levels (ABC) should be controlled to prevent progression of hepatic fibrosis in $\mathrm{T}_{2} \mathrm{D}[70]$.

\section{Acknowledgement}

This research was supported by AMED under Grant Number 19fk0210040h0002.

\section{References}

1. Bertuccio P, Turati F, Carioli G, Rodriguez T, La Vecchia C, et al. (2017) Global trends and predictions in hepatocellular carcinoma mortality. J Hepatol 67(2): 302-309.

2. Tateishi R, Uchino K, Fujiwara N, , Takehara T, Okanoue T, et al. (2019) A nationwide survey on non-B, non-C hepatocellular carcinoma in Japan: 2011-2015 update. J Gastroenterol 54(4): 367-376.

3. El Serag HB, Hampel H, Javadi F (2006) The association between diabetes and hepatocellular carcinoma: A systematic review of epidemiologic evidence. Clin Gastroenterol Hepatol 4(3): 369-380.

4. Wang C, Wang X, Gong G, Ben Q, Qiu W, et al. (2012) Increased risk of hepatocellular carcinoma in patients with diabetes mellitus: A systematic review and meta-analysis of cohort studies. Int J Cancer 130(7): 1639-1648.

5. Simon TG, King LY, Chong DQ Nguyen LH, Ma Y, et al. (2018) Diabetes, metabolic comorbidities and risk of hepatocellular carcinoma: Results from two prospective cohort studies. Hepatology 67(5): 1797-1806.

6. Chen Y, Wu F, Saito E, Lin Y, Song M, et al. (2017) Association between type 2 diabetes and risk of cancer mortality: A pooled analysis of over 771,000 individuals in the Asia Cohort Consortium. Diabetologia 60(6): 1022-1032.

7. Nakamura J, Kamiya H, Haneda M, Inagaki N, Tanizawa Y, et al. (2017) Causes of death in Japanese patients with diabetes based on the results of a survey of 45,708 cases during 2001-2010: Report of the committee on causes of death in diabetes mellitus. J Diabetes Investig 8(3): 397410 .

8. Si WK, Chung JW, Cho J, Baeg JY, Jang ES, et al. (2016) Predictors of increased risk of hepatocellular carcinoma in patients with type 2 diabetes. PLoS One 11: e0158066.

9. Ueyama M, Nishida N, Korenaga M, Korenaga K, Kumagai E, et al. (2016) The impact of PNPLA3 and JAZF1 on hepatocellular carcinoma in nonviral hepatitis patients with type 2 diabetes mellitus. J Gastroenterol 51(4): 370-379. 
10. Younossi ZM, Koenig AB, Abdelatif D, Fazel Y, Henry L, et al. (2016) Global epidemiology of nonalcoholic fatty liver disease-meta-analytic assessment of prevalence, incidence, and outcomes. Hepatology 64(1): 73-84.

11. Angulo P, Kleiner DE, Dam Larsen S, Adams LA, Bjornsson ES, et al. (2015) Liver fibrosis, but no other histologic features, is associated with long-term outcomes of patients with nonalcoholic fatty liver disease. Gastroenterology 149(2): 389-397.

12. Diehl AM, Day C (2017) Cause, pathogenesis, and treatment of nonalcoholic steatohepatitis. N Engl J Med 377(21): 2063-2072.

13. Williams CD, Stengel J, Asike MI, Torres DM, Shaw J, et al. (2011) Prevalence of nonalcoholic fatty liver disease and nonalcoholic steatohepatitis among a largely middle-aged population utilizing ultrasound and liver biopsy: A prospective study. Gastroenterology 140(1): 124-131.

14. Hashimoto E, Tokushige K (2011) Prevalence, gender, ethnic variations, and prognosis of NASH. J Gastroenterol 46 Suppl 1: 63-69.

15. Al Bahrani R, Tuertcher D, Zailaie S, Abuetabh Y, Nagamori S, et al. (2015) Differential SIRT1 expression in hepatocellular carcinomas and cholangiocarcinoma of the liver. Ann Clin Lab Sci 45(1): 3-9.

16. Farcas M, Gavrea AA, Gulei D, Ionescu C, Irimie A, et al. (2019) SIRT1 in the development and treatment of hepatocellular carcinoma. Frontiers in nutrition 6: 148 .

17. (2018) Increased risk for obesity and diabetes with neurodegeneration in developing countries. Top 10 Contribution on Genetics. Chapter 1, EBook.

18. Martin IJ (2018) Sirtuin 1, a diagnostic protein marker and its relevance to chronic disease and therapeutic drug interventions. EC Pharmacology and Toxicology 6(4): 209-215.

19. (2015) Unhealthy nutrigenomic diets accelerate NAFLD and adiposity in global communities. Journal of Molecular and Genetic Medicine 9(1).

20. Kawamura Y, Arase Y, Ikeda K, Seko Y, Imai N, et al. (2012) Large-scale long-term follow-up study of Japanese patients with non-alcoholic Fatty liver disease for the onset of hepatocellular carcinoma. Am J Gastroenterol 107(2): 253-261.

21. Seko Y, Sumida Y, Tanaka S, Mori K, Taketani H, et al. (2017) Development of hepatocellular carcinoma in Japanese patients with biopsy-proven non-alcoholic fatty liver disease: Association between PNPLA3 genotype and hepatocarcinogenesis/fibrosis progression. Hepatol Res 47(11): 1083-1092.

22. Dulai PS, Singh S, Patel J, Soni M, Prokop LJ, et al. (2017) Increased risk of mortality by fibrosis stage in nonalcoholic fatty liver disease: Systematic review and meta-analysis. Hepatology 65(5): 1557-1565.

23. Chalasani N, Younossi Z, Lavine JE, Charlton M, Cusi K, et al. (2018) The diagnosis and management of nonalcoholic fatty liver disease: Practice guidance from the American association for the study of liver diseases. Hepatology 67(1): 328-357.

24. Petta S, Di Marco V, Camma C, Butera G, Cabibi D, et al. (2011) Reliability of liver stiffness measurement in non-alcoholic fatty liver disease: The effects of body mass index. Aliment Pharmacol Ther 33(12): 1350-1360.

25. Wong VW, Vergniol J, Wong GL, Foucher J, Chan AW, et al. (2012) Liver stiffness measurement using XL probe in patients with nonalcoholic fatty liver disease. Am J Gastroenterol 107(12): 1862-1871.

26. Afdhal NH, Bacon BR, Patel K, Lawitz EJ, Gordon SC, et al. (2015) Accuracy of fibroscan, compared with histology, in analysis of liver fibrosis in patients with hepatitis B or C: A United States multicenter study. Clin Gastroenterol Hepatol 13(4): 772-779.

27. Yoneda M, Yoneda M, Mawatari H, Fujita K, Endo H, et al. (2008) Noninvasive assessment of liver fibrosis by measurement of stiffness in patients with nonalcoholic fatty liver disease (NAFLD). Dig Liver Dis 40(5): 371-378.

28. Park CC, Nguyen P, Hernandez C, Bettencourt R, Ramirez K, et al. (2017) Magnetic resonance elastography vs transient elastography in detection of fibrosis and noninvasive measurement of steatosis in patients with biopsy-proven nonalcoholic fatty liver disease. Gastroenterology152(3): 598-607.

29. Cassinotto C, Boursier J, de Ledinghen V, Lebigot J, Lapuyade B, et al. (2016) Liver stiffness in nonalcoholic fatty liver disease: A comparison of supersonic shear imaging, FibroScan, and ARFI with liver biopsy. Hepatology 63(6): 1817-1827.

30. Nobili V, Vizzutti F, Arena U, Abraldes JG, Marra F, et al. (2008) Accuracy and reproducibility of transient elastography for the diagnosis of fibrosis in pediatric nonalcoholic steatohepatitis. Hepatology 48(2): 442-448.

31. Wong VW, Vergniol J, Wong GL, Foucher J, Chan HL, et al. (2010) Diagnosis of fibrosis and cirrhosis using liver stiffness measurement in nonalcoholic fatty liver disease. Hepatology 51(2): 454-462.

32. Gaia S, Carenzi S, Barilli AL, Bugianesi E, Smedile A, et al. (2011) Reliability of transient elastography for the detection of fibrosis in nonalcoholic fatty liver disease and chronic viral hepatitis. J Hepatol 54(1): 64-71.

33. Naveau S, Lamouri K, Pourcher G, Njiké Nakseu M, Ferretti S, et al. (2014) The diagnostic accuracy of transient elastography for the diagnosis of liver fibrosis in bariatric surgery candidates with suspected NAFLD. Obes Surg 24(10): 1693-1701.

34. Kwok R, Tse YK, Wong GL, Ha Y, Lee AU, et al. (2014) Systematic review with meta-analysis: non-invasive assessment of non-alcoholic fatty liver disease--the role of transient elastography and plasma cytokeratin-18 fragments. Aliment Pharmacol Ther 39(3): 254-269.

35. Fraquelli M, Rigamonti C, Casazza G, Conte D, Donato MF, et al. (2007) Reproducibility of transient elastography in the evaluation of liver fibrosis in patients with chronic liver disease. Gut 56(7): 968-973.

36. Castera L, Foucher J, Bernard PH, Carvalho F, Allaix D, et al. (2010) Pitfalls of liver stiffness measurement: a 5-year prospective study of 13,369 examinations. Hepatology 51(3): 828-835.

37. Sirli R, Sporea I, Bota S, Jurchis A (2013) Factors influencing reliability of liver stiffness measurements using transient elastography (M-probe)monocentric experience. Eur J Radiol 82(8): e313-316.

38. Okajima A, Sumida Y, Taketani H, Hara T, Seko Y et al. (2017) Liver stiffness measurement to platelet ratio index predicts the stage of liver fibrosis in non-alcoholic fatty liver disease. Hepatol Res 47(8): 721-730.

39. Chen J, Talwalkar JA, Yin M, Glaser KJ, Sanderson SO, et al. (2011) Early detection of nonalcoholic steatohepatitis in patients with nonalcoholic fatty liver disease by using MR elastography. Radiology 259(3): 749-756.

40.Venkatesh SK, Wang G, Teo LL, Ang BW (2014) Magnetic resonance elastography of liver in healthy Asians: normal liver stiffness quantification and reproducibility assessment. J Magn Reson Imaging 39(1): 1-8.

41. Yin M, Talwalkar JA, Glaser KJ, Manduca A, Grimm RC, et al. (2007) Assessment of hepatic fibrosis with magnetic resonance elastography. Clin Gastroenterol Hepatol 5(10): 1207-1213.

42. Hsu C, Caussy C, Imajo K, Chen J, Singh S, et al. (2019) Magnetic resonance vs transient elastography analysis of patients with nonalcoholic fatty liver disease: a systematic review and pooled analysis of individual participants. Clin Gastroenterol Hepatol 17(4): 630-637.

43. Imajo K, Kessoku T, Honda Y, Tomeno W, Ogawa Y, et al. (2016) Magnetic resonance imaging more accurately classifies steatosis and fibrosis in patients with nonalcoholic fatty liver disease than transient elastography. Gastroenterology 150(3): 626-637. 
44. Park CC, Nguyen P, Hernandez C, Bettencourt R, Ramirez K, et al. (2017) Magnetic resonance elastography vs transient elastography in detection of fibrosis and noninvasive measurement of steatosis in patients with biopsy-proven nonalcoholic fatty liver disease. Gastroenterology 152(3): 598-607.

45. Huwart L, Sempoux C, Vicaut E, Salameh N, Annet L, et al. (2008) Magnetic resonance elastography for the noninvasive staging of liver fibrosis. Gastroenterology 135(1): 32-40.

46. Angulo P, Keach JC, Batts KP, Lindor KD (1999) Independent predictors of liver fibrosis in patients with nonalcoholic steatohepatitis. Hepatology $30(6): 1356-1362$.

47. Nakahara T, Hyogo H, Yoneda M, Sumida Y, Eguchi Y, et al. (2014) Type 2 diabetes mellitus is associated with the fibrosis severity in patients with nonalcoholic fatty liver disease in a large retrospective cohort of Japanese patients. J Gastroenterol 49(11): 1477-1484.

48. Fujii H, Imajo K, Yoneda M, Nakahara T, Japan study group of nonalcoholic fatty liver disease, et al. (2019) HOMA-IR: An independent predictor of advanced liver fibrosis in nondiabetic non-alcoholic fatty liver disease. J Gastroenterol Hepatol 34(8): 1390-1395.

49. Labenz C, Huber Y, Kalliga E, Nagel M, Ruckes C, et al. (2018) Predictors of advanced fibrosis in non-cirrhotic non-alcoholic fatty liver disease in Germany. Aliment Pharmacol Ther 48(10): 1109-1116.

50. Adams LA, Sanderson S, Lindor KD, Angulo P (2005) The histological course of nonalcoholic fatty liver disease: A longitudinal study of 103 patients with sequential liver biopsies. J Hepatol 42(1): 132-138.

51. Tada T, Toyoda H, Sone Y, Yasuda S, Miyake N, et al. (2019) Type 2 diabetes mellitus: A risk factor for progression of liver fibrosis in middle-aged patients with non-alcoholic fatty liver disease. J Gastroenterol Hepatol 34(11): 2011-2018.

52. Tang H, Dai Q, Shi W, Zhai S, Song Y, et al. (2017) SGLT2 inhibitors and risk of cancer in type 2 diabetes: A systematic review and meta-analysis of randomised controlled trials. Diabetologia 60(10): 1862-1872.

53. Hamaguchi E, Takamura T, Sakurai M, Mizukoshi E, Zen Y, et al. (2010) Histological course of nonalcoholic fatty liver disease in Japanese patients: tight glycemic control, rather than weight reduction, ameliorates liver fibrosis. Diabetes care 33(2): 284-286.

54. Kim Y, Chang Y, Cho YK, Ahn J, Shin H, et al. (2019) Obesity and weight gain are associated with progression of fibrosis in patients with nonalcoholic fatty liver disease. Clin Gastroenterol Hepatol 17(3): 543-550.

55. Daijo K, Nakahara T, Inagaki Y, Nanba M, Nishida Y, et al. (2020) Risk factors for histological progression of non-alcoholic steatohepatitis analyzed from repeated biopsy cases. J Gastroenterol Hepatol.

56. Younossi ZM, Golabi P, de Avila L, Paik JM, Srishord M, et al. (2019) The global epidemiology of NAFLD and NASH in patients with type 2 diabetes: A systematic review and meta-analysis. J Hepatol 71(4): 793801.

57. Bian H, Zhu X, Xia M, Yan H, Chang X, et al. (2020) Impact Of type 2 diabetes on nonalcoholic steatohepatitis and advanced fibrosis in patients with nonalcoholic fatty liver disease. Endocr Pract.
58. de Lédinghen V, Vergniol J, Gonzalez C, Foucher J, Maury E, et al. (2012) Screening for liver fibrosis by using FibroScan( $($ ) $)$ and FibroTest in patients with diabetes. Dig Liver Dis 44(5): 413-418.

59. Casey SP, Kemp WW, McLean CA, Topliss DJ, Adams LA, et al. (2012) A prospective evaluation of the role of transient elastography for the detection of hepatic fibrosis in type 2 diabetes without overt liver disease. Scand J Gastroenterol 47(7): 836-841.

60. Sobhonslidsuk A, Pulsombat A, Kaewdoung P, Petraksa S (2015) Nonalcoholic fatty liver disease (NAFLD) and significant hepatic fibrosis defined by non-invasive assessment in patients with type 2 diabetes. Asian Pac J Cancer Prev 16(5): 1789-1794.

61. Kwok R, Choi KC, Wong GL, Zhang Y, Chan HL, et al. (2016) Screening diabetic patients for non-alcoholic fatty liver disease with controlled attenuation parameter and liver stiffness measurements: A prospective cohort study. Gut 65(8): 1359-1368.

62. Roulot D, Roudot Thoraval F, NKontchou G, Kouacou N, Costes JL, et al. (2017) Concomitant screening for liver fibrosis and steatosis in French type 2 diabetic patients using Fibroscan. Liver Int 37(12): 1897-1906.

63. Lai LL, Wan Yusoff WNI, Vethakkan SR, Nik Mustapha NR, Mahadeva S, et al. (2019) Screening for non-alcoholic fatty liver disease in patients with type 2 diabetes mellitus using transient elastography. J Gastroenterol Hepatol 34(8): 1396-1403.

64. Demir M, Deyneli O, Yllmaz Y (2019) Screening for hepatic fibrosis and steatosis in Turkish patients with type 2 diabetes mellitus: A transient elastography study. Turk J Gastroenterol 30(3): 266-270.

65. Mantovani A, Turino T, Lando MG, Gjini K, Byrne CD, et al. (2019) Screening for non-alcoholic fatty liver disease using liver stiffness measurement and its association with chronic kidney disease and cardiovascular complications in patients with type 2 diabetes. Diabetes Metab.

66. Mansour A, Mohajeri Tehrani MR, Samadi M, Gerami H, Qorbani M, et al. (2019) Risk factors for non-alcoholic fatty liver disease-associated hepatic fibrosis in type 2 diabetes patients. Acta Diabetol 56(11): 11991207.

67. Lee HW, Wong GL, Kwok R, Choi KC, Chan CK, et al. (2020) Serial transient elastography examinations to monitor patients with type 2 diabetes: A prospective cohort study. Hepatology.

68. Doycheva I, Cui J, Nguyen P, Costa EA, Hooker J, et al. (2016) Non-invasive screening of diabetics in primary care for NAFLD and advanced fibrosis by MRI and MRE. Aliment Pharmacol Ther 43(1): 83-95.

69. Kang KA, Jun DW, Kim MS, Kwon HJ, Nguyen MH (2020) Prevalence of significant hepatic fibrosis using magnetic resonance elastography in a health check-up clinic population. Aliment Pharmacol Ther 51(3): 388396.

70.Sumida Y, Yoneda M (2018) Current and future pharmacological therapies for NAFLD/NASH. J Gastroenterol 53(3): 362-376.

For possible submissions Click below:

Submit Article 